\title{
Quem conta um causo merece aplauso: prática interdisciplinar em sala de aula como parâmetro de aprendizagem.
}

Sarah Pereira Santos ${ }^{1}$; Guilhermina Reis Silva²; Raphael Euzebio³; Geiza Pereira de Assunção4; Geraldo Sadoyama Leal 5; Leonardo Santos Andrade ${ }^{6}$; Paulo Alexandre de Castro ${ }^{7}$; Adriana dos Santos Prado Sadoyama ${ }^{8}$

\section{Resumo}

A educação brasileira enfrenta atualmente um grande desafio: minimizar as dificuldades da leitura e escrita desde a alfabetização. Muitas vezes os conteúdos apresentados aos educandos não são contextualizados e na prática se tornam fragmentados e fora da realidade. Nesse caso, a prática interdisciplinar é um importante parâmetro de aprendizagem. O presente trabalho tem como objetivo apresentar uma proposta: utilizar o gênero "causo" em sala de aula de forma interdisciplinar para melhorar e incentivar a leitura e a escrita. Além disso, a valorização e respeito aos traços culturais da comunidade bem como a variação linguística, são pontos interessantes das atividades que foram desenvolvidas em uma turma de 36 alunos do quinto ano do Colégio Anice Cecílio Pedreiro. Foi realizada uma sequência didática de quatro aulas onde os alunos assistiram vídeos dos causos: causo da melancia, causo do ovo e causo da bicicleta. Aconteceu uma roda de conversa em que os mesmos apresentaram resultados de suas pesquisas. $\mathrm{Na}$ oportunidade contaram causos trazidos de casa, encenaram e debateram

1 Discente do PIBID-Interdisciplinar - Regional Catalão/Universidade Federal de Goiás (sarahpds50@gmail.com)

2 Professor Supervisor do PIBID-Interdisciplinar - Regional Catalão/Universidade Federal de Goiás

3 Discente do PIBID-Interdisciplinar - Regional Catalão/Universidade Federal de Goiás

4 Discente do PIBID-Interdisciplinar - Regional Catalão/Universidade Federal de Goiás

5 Coordenadora do PIBID-Interdisciplinar - Regional Catalão/Universidade Federal de Goiás

6 Coordenadora do PIBID-Interdisciplinar - Regional Catalão/Universidade Federal de Goiás

7 Coordenadora do PIBID-Interdisciplinar - Regional Catalão/Universidade Federal de Goiás

8 Coordenadora do PIBID-Interdisciplinar - Regional Catalão/Universidade Federal de Goiás 
sobre a linguagem utilizada e a importância de resgatar esse hábito milenar. Algumas atividades interdisciplinares foram realizadas em matemática: após os vídeos, a melancia que foi levada para a sala de aula, foi fracionada revisando assim a noção de fração. Em ciências foi mencionado as vantagens para o organismo humano na ingestão de melancia. Espera-se que ocorra um aumento nas habilidades que envolvam outras disciplinas, que os alunos consigam contextualizar e estabelecer relações entre os conteúdos apreendidos. Conclui-se que, ao desenvolver as atividades, foi observado um interesse maior dos alunos na leitura, escrita, oralidade e compreensão do texto.

Apoio: PIBID/CAPES

Palavras Chave: Prática interdisciplinar; gênero textual; interesse. 